Review Article

\section{Fluorinated nematicides: Novel classes in the way}

\author{
Mohamed S Khali|* and Rasha E Selim
}

Agricultural Research Center, Central Agricultural Pesticides Laboratory (CAPL), El- Sabaheya, Alexandria, Egypt

\section{Abstract}

The demand on non- fumigant nematicides was strongly increased in the last few years, and this interesting in nematicides are due to farmers are needed for safer pesticides and increasing of the regulatory pressure on many of the traditional nematicides. The control of plant parasitic nematodes with synthetic nematicides is the most widespread and preferred method, but not always effective enough. The most of synthetic nematicides especially non-fumigants are high toxic to non-target organisms. Thus, Novel non-fumigant nematicides were appeared as alternatives.

The group of trifluoromethyl contains both fluensulfone and fluopyram which are different in mode of action than traditional nematicides as organophosphate and carbamate. Meanwhile, results indicated that fluensulfone and fluopyram are promising nematicides. These new nematicides are very different from traditional nematicides; they are more selective, less toxic and safer to use.

\section{More Information}

*Address for Correspondence: Dr. Mohamed Salah Khalil, Researcher, Agricultural Research Center, Central Agricultural Pesticides Laboratory, Fungicides, Bactericides and Nematicides Department, Tel: 002/0100-929-7847;

Email: melonema@gmail.com

Submitted: January 27, 2021

Approved: February 18, 2021

Published: February 19, 2021

How to cite this article: Khalil MS, Selim RE. Fluorinated nematicides: Novel classes in the way. J Plant Sci Phytopathol. 2021; 5: 014-016.

DOI: 10.29328/journal.jpsp.1001055

Copyright: @ 2021 Khalil MS, et al. This is an open access article distributed under the Creative Commons Attribution License, which permits unrestricted use, distribution, and reproduction in any medium, provided the original work is properly cited.

Keywords: Nematicides; Fluensulfone, Fluopyram

(D) Check for updates

(8) OPEN ACCESS

\section{Introduction}

Around the world, farmers are usually depending on fumigant or non-fumigant nematicides such as methyl bromide, several organophosphates (fosthiazate, ethoprophos and fenamiphos) and carbamate (oxamyl) to manage plant parasitic nematodes. The expanded use in chemical nematicides is due to their prompt efficacy, easy in application and the relatively low cost $[1,2]$. The extensive use of the traditional nematicides causes certain environmental and resistance problems, which cause a kind of restriction in the usage, therefore new classes of nematicides are become needed.

Fluensulfone and fluopyram both are new nematicides which have at least three fluorine atoms in their molecular structure (3-F nematicides), in addition they are much safer in their toxicity profile than older nematicides [3]. Fluensulfone is one of new non-fumigant nematicides which belong to fluoroalkenyle class that was registered in the USA during 2014. Moreover, Fluensulfone is safer than nematostatic organophosphates and carbamates, as well as has low toxicity to non-target organisms [4-6], however, fluensulfone use as soil application, while foliar application as systemic action against nematodes still under investigation. Fluensulfone is irreversible nematicide which affecting the nematodes mobility [7].
In the same context, fluopyram is a new nematicide that has been recently registered under various trade names. It was first discovered and registered as a fungicide, but recently has been registered as a nematicide. Fluopyram has effect on the mobility of nematodes, presenting nematostatic action in species of M. incognita and Rotylenchulus reniformis [3]. Therefore, in this review we aimed to throw a light on new classes of nematicides, as well as, their usage and properties.

\section{Fluoroalkenyl sulfone class}

Recently, new nematicide was registered and this compound namely, Fluensulfone (CAS No. 318290-98-1; 5-chloro-2-(3,4,4-trifluorobut-3-enylsulfonyl)-1,3-thiazole), which belonging to the fluoroalkenyl class [8,9]. This compound produced by Adama Agricultural Solutions Ltd, and was registered in EPA during 2014. Fluensulfone (Nimitz ${ }^{\circledR}$ ) was approved as a nematicide on tomatoes, peppers, eggplants, cucumbers, potato, carrot, sugarcane, watermelons, okra and cantaloupe.

Fluensulfone appears as a white fine crystalline powder with melting point of $34.4^{\circ} \mathrm{C}$. It has a $\operatorname{low} \log P_{\text {ow }}(1.96)$ and the water solubility was $545.3 \mathrm{mg} \mathrm{l}^{-1}$ at $20^{\circ} \mathrm{C}$ [10]. Therefore, this compound has good systemicity and soil movement can be expected. The degradation half-life $\left(\mathrm{DT}_{50}\right)$ was range from 11 to 22 days [7]. Moreover, the half-life of fluensulfone by 
light (photo-degradation) in water not exceeded 1 day and it is stable to hydrolysis.

However, the environmental profile mentions that fluensulfone nontoxic to Birds, Honeybee, and Earthworms, while it was slightly toxic to fish of freshwater. Fluensulfone has moderate toxicity against invertebrates of freshwater, but it was highly toxic to freshwater green algae [11].

On the other hand, fluensulfone mode of action (MoA) was depending on the inhibition of medium-chain acyl CoA dehydrogenases, which play a major role in mobilization of lipids on which nematodes rely for energy [12-14]. Moreover, inhibition in egg laying, egg hatching, development, feeding and locomotion were recorded with fluensulfone in nematode, Caenorhabditis elegans [15]. Also, derivatives of difluoroalkenyl group recorded inhibition in $\beta$-oxidation of fatty acids in the mitochondria [16].

According to various investigations, the nematicidal efficacy of fluensulfone included; root-knot nematodes (Meloidogyne incognita, Meloidogyne hapla and Meloidogyne javanica), Potato cyst nematode (Globodera pallida), Soybean cyst nematode (Heterodera glycines), Sting nematode (Belonolaimus spp.), Stubby-root nematode (Trichodorus spp.), Stem nematode (Ditylenchus spp.) and root lesion nematode (Pratylenchus penetrans) [11,17,18].

Fluensulfone (Nimitz ${ }^{\circledR}$ ) was formulated as $48 \%$ EC and used at the rate of 2 to $4 \mathrm{l}$ / acres depending on several factors such as nematode population levels, crop rotation scheme and selection of susceptible or resistant cultivars. Nimitz ${ }^{\circledR} 48 \%$ was applied through drip injection and broadcast or banding with mechanical incorporation. Fluensulfone (Nimitz $\left.{ }^{\circledR}\right)$ has recommended as a single application 7 days prior to transplanting to ensure both performance and crop safety [19].

\section{Pyridinyl-ethyl-benzamide class}

Fluopyram (CAS No.658066-35-4; N-[2-[3-chloro-5(trifluoromethyl)-2-pyridinyl] ethyl]-2- (trifluoromethyl) benzamide), is a new broad spectrum nematicide belonging to the pyridinyl-ethyl-benzamide class which mainly use as a fungicide. Fluopyram was discovered, developed and produced by Bayer Crop Science as a broad spectrum fungicide (Luna ${ }^{\circledR}$ ) [20] and introduced globally as a nematicide in 2013 under the trade name Verango ${ }^{\circledR}$ in Honduras for use on bananas as a drench application [21] (Figure 1).

During 2014 Bayer received approval from the US EPA<smiles>O=S(=O)(CCC(F)=C(F)F)c1ncc(Cl)s1</smiles>

for fluopyram as ILevo $^{\circledR}$ a soybean seed treatment product for control of sudden death syndrome (SDS), providing also control of nematodes in the seed zone. While in 2015 approval was granted in the United States for the insecticide/ nematicide Velum Total ${ }^{\circledR}$. This product, containing fluopyram and imidacloprid, provides control of all economically relevant nematodes and early season insects in cotton and peanuts.

Fluopyram has melting point of $118^{\circ} \mathrm{C}$ and its boiling point is $319^{\circ} \mathrm{C}$. Also, it has a low $\log P_{o w}$ (3.3) and the water solubility was $16 \mathrm{mg} \mathrm{l}^{-1}$ at $20^{\circ} \mathrm{C}$ (Clarke and Delaney 2003). While vapor pressure $\left(P_{a}\right.$ at $\left.20^{\circ} \mathrm{C}\right) 1.2 \times 10^{-6}$ [22].

According to Rieck and Coqueron [20] fluopyram is a new subclass of complex II respiration inhibitors (FRAC, group7), which belongs to succinate dehydrogenase inhibitors (SDHI). In nematodes the compound has been described to inhibit mitochondrial respiration quinone-dependent succinate reductase (complex II - SQR inhibition), which leads to a fast and severe depletion of the nematode's cellular energy (adenosine triphosphate, ATP) [23,24].

Certain genera of plant parasitic nematodes are controlled significantly by fluopyram including; Globodera spp, Radopholus spp, Rotyenchulus reniformis Pratylenchus spp, Helicotylenchus spp. In addition, the root-knot nematode, Meloidogyne incognita and the soybean cyst nematode, Heterodera glycines $[4,17,18,25-27]$.

Fluopyram $\left(\right.$ Velum $^{\circledR}$ ) was formulated as $40 \%$ SC which is suitable for foliar, soil and seed treatment applications. Fluopyram is limited in xylem movement, thus the direct contact is important for suppression nematodes. Fluopyram recommended on potatoes, tomatoes, sweet potatoes, cucumber, melon, zucchini, carrots, coffee, bananas, corn, cotton, soybean, sugarcane and cucurbits as well as tobacco $[23,28]$ (Figure 2).

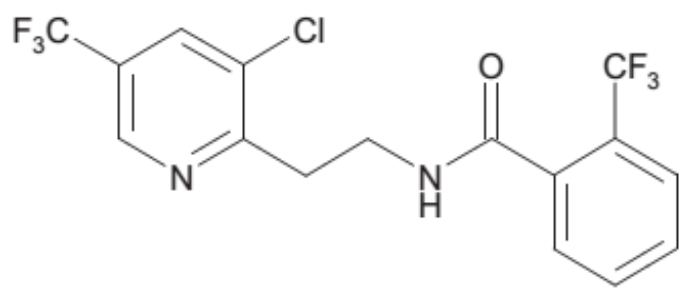

Figure 2: Fluopyram structure.

\section{References}

1. Khalil MS, Darwesh DM. Some integrated practices to manage rootknot nematodes on tomatoes: A Mini Review. Innovat Techniq Agric. 2018; 3: 618-625.

2. Abd El-Aziz MH, Khalil MS. Antiviral and Antinematodal potentials of chitosan: Review. J Plant Sci Phytopathol. 2000; 4: 55-59. https://www.heighpubs.org/jpsp/jpsp-aid1051.php

3. Desaeger JA, Watson TT. Evaluation of new chemical and biological 
nematicides for managing Meloidogyne javanica in tomato production and associated double-crops in Florida. Pest Manag Sci. 2019; 75 3363-3370.

PubMed: https://pubmed.ncbi.nlm.nih.gov/31074102/

4. Faske TR, Hurd K. Sensitivity of Meloidogyne incognita and Rotyenchulus reniformis to fluopyram. J Nematol. 2015; 47: 316-321. PubMed: https://pubmed.ncbi.nlm.nih.gov/26941460/

5. Morris KA, Langston DB, Dickson DW, Davies RF, Timper $P$, et al Efficacy of fluensulfone in a tomato-cucumber double cropping system. J Nematol. 2016; 47: 310-315.

PubMed: https://pubmed.ncbi.nlm.nih.gov/26941459/

6. Morris KA, Langston DB, Davis RF, Noe JP, Dickson, et al. Efficacy of various application methods of fluensulfone for managing root-knot nematodes in vegetables. J Nematology. 2016; 48: 65-71.

PubMed: https://pubmed.ncbi.nlm.nih.gov/27418698/

7. Oka Y, Shuker S, Tkachi N. Nematicidal efficacy of MCW-2, a new nematicide of the fluoroalkenyl group, against the root-knot nematode Meloidogyne javanica. Pest Manage. 2009; Sci. 65: 1082-1089. PubMed: https://pubmed.ncbi.nlm.nih.gov/19488996/

8. Jeanmart S, Edmunds EF, Lamberth C, Pouliot M. Synthetic approaches to the 2010-2014 new agrochemicals. Bioorg Med Chem. 2016; 24: 317-341.

PubMed: https://pubmed.ncbi.nlm.nih.gov/26725441/

9. Maienfisch $P$, Edmunds AJF. Thiazole and isothiazole ring containing compounds in crop protection. In: Advances in Heterocyclic Chemistry. (edS. E.F.V. Scriven and C.A. Ramsden), 2017; 21: 35-88.

10. Australian Pesticides and Veterinary Medicines Authority. Evaluation of the new active Fluensulfone in the product Nimitz 480 EC nematicide. 2015. http://apvma.gov.au/node/15611.

11. Dent JA, Smith MM, Vassilatis DK, Avery L. The genetics of ivermectin resistance in Caenorhabditis elegans. Proc Nat Acad Sci. U.S.A. 2000; 97: 2674-2679.

PubMed: https://pubmed.ncbi.nlm.nih.gov/10716995/

12. Lai MT, Liu LD, Liu HW. J Am Chem Soc. 1991; 113: 7388-7397.

13. Dakoji S, Shin I, Becker DF, Stankovich MT, Liu H, et al. Studies of Acyl-CoA Dehydrogenase Catalyzed Allylic Isomerization: A One-Base or Two-Base Mechanism? J Am Chem Soc. 1996; 118: 10971-10979.

14. Mansoorabadi SO, Thibodaux CJ, Liu HW. The diverse roles of flavin coenzymes--nature's most versatile thespians. J Org Chem. 2007; 72
6329-6342.

PubMed: https://pubmed.ncbi.nlm.nih.gov/17580897/

15. Kearn J, Ludlow E, Dillon J, O'Connor V, Holden-Dye L, et al. Fluensulfone is a nematicide with a mode of action distinct from anticholinesterases and macrocyclic lactones. Pesticides Biochem Physiol. 2014; 109: 44-57.

PubMed: https://pubmed.ncbi.nlm.nih.gov/24581383/

16. Pitterna $T$, Boeger M, Maienfisch P. gem-Difluorovinyl Derivatives as Insecticides and Acaricides. Chimia. 2004; 58: 108-116.

17. Dahlin P, Eder R, Consoli E, Krauss J, Kiewnick S. Integrated control of Meloidogyne incognita in tomatoes using fluopyram and Purpureocillium lilacinum strain 251. Crop Protection. 2019; 124: 1-7.

18. Yue X, Li F, Wang B. Activity of four nematicides against Meloidogyne incognita race 2 on tomato plants. J Phytopathol. 2000; 168: 399-404.

19. Oka Y, Berson M, Barazani A. Proceedings, 5th International Congress of Nematology (13-18 July), Brisbane, Australia. 2008; 313-314.

20. Rieck H, Coqueron PY. Modern Crop Protection Compounds, Insecticides, Vol. 3 (eds. W. Krämer, U. Schirmer, P. Jeschke and M. Witschel), Weinheim, Germany: Wiley. VCH. 2012; 639-645.

21. McDougall P. Industry Overview (Market). 2014. https://www. phillipsmcdougall.com/home

22. Clarke ED, Delaney JS. Physical and Molecular Properties of Agrochemicals: An Analysis of Screen Inputs, Hits, Leads, and Products Chimia. 2003; 57: 731-734.

23. Broeksma A, Puetzkuhl K, Lamprecht S, Fuersch H. Velum ${ }^{\circledR}$. An evolutionary nematicide for efficient crop production. J Nematol. 2014; 46: $140-141$.

24. Luemmen $P$, Huang LS, Lisse D, Berry EA. $248^{\text {th }}$ ACS National Meeting \& Exposition (10-14 August 2014), San Francisco, CA, USA. Abstracts of Papers, AGRO. 131. 2014.

25. Burrows PR, Kerry BR, Perry RN. J Zool Lond. 1994; 232: 341-346.

26. Slaats BE. Investigations on the efficacy of encapsulation of the endoparasitic fungus Hirsutella rhossiliensis for control of plantparasitic nematodes. Gottingen: V \& R Uni press GmbH. 2008; 135.

27. Bayer Crop Science. Press release. 2009. www.bayercropscience.com

28. Bayer Crop Science. News Release. 2015. http://news.agropages. com/News/ 